\title{
Long-Term Alterations in Neuroimmune Responses after Neonatal Exposure to Lipopolysaccharide
}

\author{
Lysa Boissé, Abdeslam Mouihate, Shaun Ellis, and Quentin J. Pittman \\ Calgary Brain Institute, Department of Physiology and Biophysics, University of Calgary, Calgary, Alberta T2N 4N1, Canada
}

Fever is an integral part of the host's defense to infection that is orchestrated by the brain. A reduced febrile response is associated with reduced survival. Consequently, we have asked if early life immune exposure will alter febrile and neurochemical responses to immune stress in adulthood. Fourteen-day-old neonatal male rats were given Escherichia coli lipopolysaccharide (LPS) that caused either fever or hypothermia depending on ambient temperature. Control rats were given pyrogen-free saline. Regardless of the presence of neonatal fever, adult animals that had been neonatally exposed to LPS displayed attenuated fevers in response to intraperitoneal LPS but unaltered responses to intraperitoneal interleukin $1 \beta$ or intracerebroventricular prostaglandin $\mathrm{E}_{2}$. The characteristic reduction in activity that accompanies fever was unaltered, however, as a function of neonatal LPS exposure. Treatment of neonates with an antigenically dissimilar LPS (Salmonella enteritidis) was equally effective in reducing adult responses to E. coli LPS, indicating an alteration in the innate immune response. In adults treated as neonates with LPS, basal levels of hypothalamic cyclooxygenase 2 (COX-2), determined by semiquantitative Western blot analysis, were significantly elevated compared with controls. In addition, whereas adult controls responded to LPS with the expected induction of COX-2, adults pretreated neonatally with LPS responded to LPS with a reduction in COX-2. Thus, neonatal LPS can alter CNS-mediated inflammatory responses in adult rats.

Key words: stress; interleukin; COX-2; cytokine; prostaglandin; fever

\section{Introduction}

There are significant differences among individuals in the severity and duration of illness caused by infectious disease, and a similar phenomenon has been observed in rats (Wachulec et al., 1997). Although some of this difference may be due to genetic and immunological diversity, other factors undoubtedly influence the capacity to combat infection. The ability to generate a fever may be one such factor.

Fever is a phylogenetically ancient response to infection that is an integral part of the host defense response (Hart, 1988). If animals are prevented from developing fever during infection, they have greater morbidity and mortality than those permitted to develop fever (Kluger et al., 1998; Jiang et al., 2000). Thus, fever (Jiang et al., 1999b) is thought to have "survival value" (Klein and Cunha, 1996), most likely because of its ability to modify cytokine expression and to reduce bacterial loads (Jiang et al., 1999a,b).

Fever is part of a physiological, hormonal, and behavioral response to inflammation that is orchestrated by the CNS. It occurs when host cells of the immune system respond to pathogen-associated molecular patterns to initiate innate immune responses. Among the best understood of these processes is that resulting from exposure to lipopolysaccharide (LPS), a com-

Received Feb. 11, 2004; revised April 7, 2004; accepted April 8, 2004.

This work was supported by the Canadian Institutes of Health Research. L.B. is an Alberta Heritage Foundation for Medical Research (AHFMR) student, and Q.J.P. is an AHFMR medical scientist. We thank Mio Tsutsui for technical assistance.

Correspondence should be addressed to Quentin J. Pittman, Calgary Brain Institute, Faculty of Medicine, University of Calgary, 3330 Hospital Drive Northwest, Calgary, Alberta T2N 4N1, Canada. E-mail: pittman@ucalgary.ca. DOI:10.1523/JNEUROSCI.1077-04.2004

Copyright $\odot 2004$ Society for Neuroscience $\quad$ 0270-6474/04/244928-07\$15.00/0 ponent of the outer membrane of Gram-negative bacteria (for review, see Blatteis et al., 2000). When exposed to LPS, immune cells synthesize inflammatory mediators such as the cytokines interleukin $1 \beta$ (IL-1 $\beta$ ), IL-6, and tumor necrosis factor $\alpha$. These cytokines induce cyclooxygenase 2 (COX-2) to synthesize prostaglandin $\mathrm{E}_{2}\left(\mathrm{PGE}_{2}\right)$ within the CNS. PGE 2 acts within the ventral-medial preoptic area and anterior hypothalamus to activate heat conservation and production mechanisms to generate fever.

Stress experienced by a neonatal rat can markedly alter its response to behavioral stress in adulthood. Even relatively subtle differences in maternal care and grooming can change a rat's stress response for its entire lifetime (for review, see Caldji et al., 2000; Meaney, 2001). Similarly, there is now intriguing evidence that some CNS-mediated immune responses can be influenced by early neonatal stressful experience. For example, physiological and behavioral stress in the neonatal period can profoundly affect the hypothalamic-pituitary-adrenal (HPA) response to noise stress and to LPS in adults (Shanks et al., 1995, 2000). This can result in altered expression of experimental arthritis (Shanks et al., 2000), altered reactivity of the hypothalamic-pituitarygonadal axis (Nilsson et al., 2002), and persistent changes in CSF neurotransmitter levels (Coplan et al., 1996; Mathew et al., 2002) and receptor phenotypes (Hsu et al., 2003; Zhang et al., 2004).

As components of the behavioral stress response are altered by neonatal LPS, it is conceivable that neonatal exposure to the immunological stressor LPS might also alter the febrile response in adulthood. Given the importance of fever to the host-defense response to infection, experiences early in life that alter fever may have a significant impact on an individual's response to infection 
well into adulthood. In this study, we test the hypothesis that neonatal immune exposure will alter febrile and neurochemical responses to LPS in adult rats.

\section{Materials and Methods}

Animals. Pregnant female Sprague Dawley rats (Charles River) were maintained at $22^{\circ} \mathrm{C}$ on a $12 \mathrm{hr}$ light/dark cycle (8 A.M. -8 P.M.), and rat chow and water were available ad libitum. On the day of birth [postnatal day $0(\mathrm{P} 0)$ ], litters were culled to 12 pups and randomly distributed among the dams. For longitudinal experiments, all litters were weaned at $21 \mathrm{~d}$, and male rats were housed four to six animals per cage until they reached 8-12 weeks of age. All procedures were in accordance with the Canadian Council on Animal Care regulations and were approved by the local University of Calgary Animal Care Committee.

Early life manipulations: neonatal body temperature measurements. To determine the dose of LPS and the ambient condition favorable for fever induction in neonatal rat pups, several groups of rat pups were surgically implanted with small wax-coated, precalibrated mini temperature transmitters (model XM-FH; Mini-Mitter Co., Sun River, OR) $10 \mathrm{~d}$ after birth (P10) under halothane anesthesia (0.5-1.5\%). All pups were given a $4 \mathrm{~d}$ recovery period, and experiments were performed on P14. On P13, dams and their pups (in their home cages) were brought into a temperaturecontrolled room to acclimatize for a $24 \mathrm{hr}$ period. The following day (P14), each pup carrying a transmitter was placed in a cage with three nonimplanted littermates. Baseline body temperatures were recorded for a minimum of $1 \mathrm{hr}$. The pups were then subjected to intraperitoneal injections of different LPS doses (50 or $100 \mu \mathrm{g} / \mathrm{kg}$ Escherichia coli, serotype O26:B6, L-3755; Sigma, St. Louis, MO) at different ambient room temperatures $\left(22\right.$ and $\left.30^{\circ} \mathrm{C}\right)$. Body temperature was recorded for a minimum of $6 \mathrm{hr}$ after the injection.

Early life manipulations: neonatal treatment for longitudinal study. Pups were culled and randomly distributed as above, although they did not undergo surgical mini transmitter placement. When the pups reached P13, they were brought to the temperature-controlled room with their dam and allowed to acclimatize to the new environment. On P14, six pups per litter were randomly selected, and LPS was administered intraperitoneally in sterile saline ( $1 \mu \mathrm{l} / \mathrm{g}$ of pup weight). Six control pups from the same dam were administered an equal volume of sterile, pyrogen-free saline. The dam was replaced in the home cage with her pups, and the animals were kept in the temperature-controlled room for another $24 \mathrm{hr}$. Once the $24 \mathrm{hr}$ period was over, the animals were returned to the animal care facility.

At a minimum, 10 different litters were used for these experiments on a minimum of four separate occasions. In addition, the neonatal treatments were performed with different rat pup litters under different conditions. In one condition, P14 pups were administered E. coli LPS (100 $\mu \mathrm{g} / \mathrm{kg}$, i.p.) at an ambient temperature of $22^{\circ} \mathrm{C}$ (as opposed to $30^{\circ} \mathrm{C}$ ). In another condition, $\mathrm{P} 14$ rat pups were administered Salmonella enteritidis LPS $(100 \mu \mathrm{g} / \mathrm{kg}$, i.p. $)$ rather than E. coli LPS. The rat pups were then replaced with their dams and treated identically to the previous groups described above.

Body temperature measurements in adulthood. At 2-3 months of age, adult rats were anesthetized with halothane (induced at $4 \%$ and maintained at $2 \%$ ), and wax-coated, precalibrated temperature transmitters (model VM-FH; Mini-Mitter Co.) or silicone-coated temperature data loggers (SubCue Dataloggers, Calgary, Alberta, Canada) were surgically implanted into the abdominal cavity. After a 5-7 d recovery period, at 11:30 A.M.-1 P.M., the rats received $50 \mu \mathrm{g} / \mathrm{kg}$ E. coli LPS intraperitoneally dissolved in sterile saline, and body temperature was recorded over a $24 \mathrm{hr}$ period. This dose of LPS has been used previously in our laboratory to elicit fevers in adult rats (Mouihate and Pittman, 1998, 2003). Control animals received an equivalent volume of sterile, pyrogen-free saline. Unless otherwise specified, LPS fevers in adulthood were always elicited with this protocol (i.e., $50 \mu \mathrm{g} / \mathrm{kg}$ E. coli LPS, i.p.). Body temperature data were recorded automatically every $5 \mathrm{~min}$ and were averaged over $15 \mathrm{~min}$ intervals. The LPS fever experiments were repeated a minimum of four times.

The telemetry transmitter also transmits activity data. Activity is de- fined as the number of gross motor movements made by the animal every $5 \mathrm{~min}$, and these values were averaged for two periods. The first value was taken from averaging $1 \mathrm{hr}$ of baseline immediately before LPS injection. The second activity value was taken by averaging the activity from 2 to 3 $\mathrm{hr}$ after injection. The second period corresponded to time at approximately the peak of the febrile response.

In a separate set of experiments, IL- $1 \beta$ fevers were induced with an intraperitoneal injection of human recombinant IL-1 $\beta\left(1 \mu \mathrm{g} / \mathrm{kg}, 10^{8}\right.$ $\mathrm{U} / \mathrm{mg}$; Immunex, Seattle, WA) in sterile saline, a protocol used previously in our laboratory to induce IL-1 $\beta$ fevers (Mouihate et al., 1998). IL-1 $\beta$ fever experiments were performed on two separate occasions, 2 years apart.

A final series of adult experiments involved treating 6-week-old adult rats with intraperitoneal $100 \mu \mathrm{g} / \mathrm{kg}$ E. coli LPS or intraperitoneal saline, after which the rats were left undisturbed for 2 months, at which time they were outfitted with data loggers as described above. After a 5-7 d recovery period, all rats received $50 \mu \mathrm{g} / \mathrm{kg}$ E. coli LPS intraperitoneally dissolved in sterile saline, and body temperature was recorded over a 24 hr period.

$P G E_{2}$ fevers. Rats were deeply anesthetized with sodium pentobarbital (Somnotol, $65 \mathrm{mg} / \mathrm{kg}$, i.p.), and a temperature transmitter was inserted into the abdominal cavity (as above). Under aseptic conditions, a $12 \mathrm{~mm}$ stainless steel guide cannula (23 gauge thin wall) was implanted stereotaxically above the upper floor of the lateral cerebral ventricle (LCV; coordinates from bregma, lateral, $-1.5 \mathrm{~mm}$; anterior, $+0.8 \mathrm{~mm}$; and vertical, $-3.7 \mathrm{~mm}$ ) and fixed in place with jeweler's screws and dental cement. A stainless steel stylus was inserted into the cannula to occlude it until experimentation. After a $7 \mathrm{~d}$ recovery period, two different series of experiments were performed to determine $\mathrm{PGE}_{2}$ responses. In one series, rats were anesthetized with urethane $(1.5 \mathrm{gm} / \mathrm{kg}$, i.p.), and their body temperatures were stabilized at $36-37^{\circ} \mathrm{C}$ as previously described (Malkinson et al., 1988; Chen et al., 1999). After baseline body temperature had been stable for a minimum of $1 \mathrm{hr}$, a 30 gauge hollow stylet connected to polyethylene tubing was lowered through the guide cannula into the LCV, and $25 \mathrm{ng}$ of $\mathrm{PGE}_{2}$ in $5 \mu \mathrm{l}$ of sterile saline was allowed to flow by gravity into the LCV. Body temperature was recorded over $1 \mathrm{hr}$. In a second series, the animals were unanesthetized, and the stylet was inserted at the beginning of the experiment. Identical infusions of $\mathrm{PGE}_{2}$ were given without the animal being aware of the intervention.

COX-2 Western blot. Two hours after adult rats were administered LPS (50 $\mu \mathrm{g} / \mathrm{kg}$, i.p.) or saline, they were deeply anesthetized with sodium pentobarbital ( $80-100 \mathrm{mg} / \mathrm{kg}$, i.p.) and perfused with $\mathrm{PBS}$ at $4^{\circ} \mathrm{C}$ via the left cardiac ventricle. The hypothalamus and preoptic area were quickly removed over ice and flash-frozen in liquid nitrogen. Brain tissue was homogenized; proteins were extracted; and $30 \mu \mathrm{g}$ aliquots were separated by $10 \%$ SDS-PAGE as previously described (Mouihate et al., 2002). Proteins were then transferred to a nitrocellulose membrane and incubated for $2 \mathrm{hr}$ at room temperature in a 1:2000 dilution of affinitypurified rabbit $\alpha$-COX-2 antibody (Ab) (catalog \#160126; Cayman Chemical, Ann Arbor, MI) in solution with a 1:40,000 dilution of affinity-purified rabbit $\alpha$-actin Ab (catalog \#A2066; Sigma) The antibodies were diluted in 5\% fat-free milk in Tris-buffered saline containing Tween 20 (TBS-T). Previous work in our laboratory has shown that preabsorption with the specific peptides eliminates band staining, and the two antibodies do not interfere with each other. The membrane was then washed for $30 \mathrm{~min}$ in TBS-T and incubated for $1 \mathrm{hr}$ in 1:4000 goat anti-rabbit IgG-horseradish peroxidase conjugate (SC-2004; Santa Cruz Biotechnology, Santa Cruz, CA) at room temperature. Bound antibodies were revealed using an enhanced chemiluminescence assay (Pierce, Rockford, IL). All samples were run twice.

Data analysis. Maximum fever temperatures were subjected to oneway ANOVA followed by Student-Neuman-Keuls post hoc analysis to reveal differences among groups. Where only two measurements were compared, an unpaired $t$ test was used. Baseline temperature means (time, -1 to $0 \mathrm{hr}$ ) were also compared statistically using ANOVAs. Proteins were quantified by densitometry to give $\mathrm{COX}-2$ /actin ratios to provide a semiquantitative value according to the amount of the housekeeping protein actin in each sample. Immunoblot data were compared using 


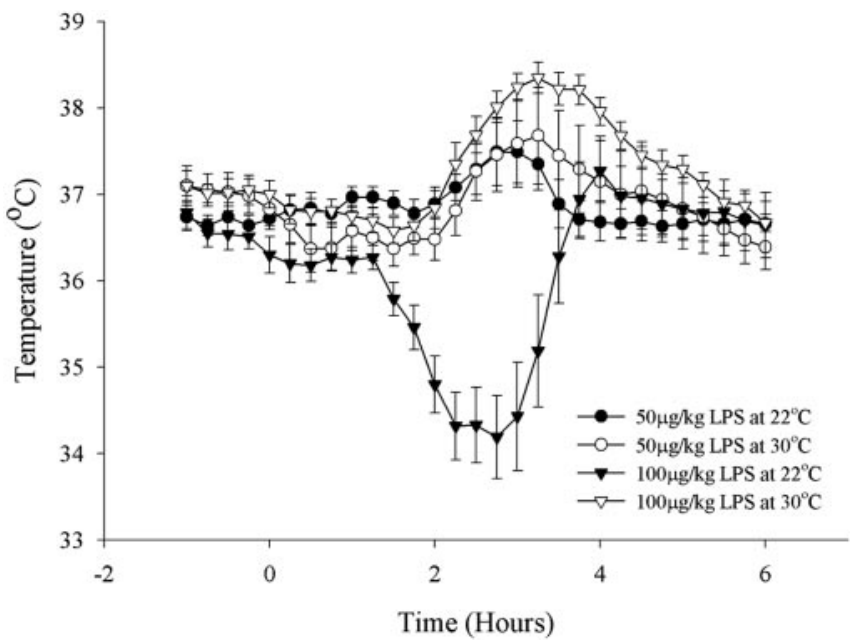

Figure 1. Body temperature responses (mean \pm SEM) of neonatal rat pups to 50 or 100 $\mu \mathrm{g} / \mathrm{kg}$ E. coli LPS, given intraperitoneally at time 0 , at an ambient temperature of 22 or $30^{\circ} \mathrm{C}$ $\left(n=6\right.$ for $50 \mu \mathrm{g} / \mathrm{kg}$ at $22^{\circ} \mathrm{C} ; n=10$ for $50 \mu \mathrm{g} / \mathrm{kg}$ at $30^{\circ} \mathrm{C} ; n=10$ for $100 \mu \mathrm{g} / \mathrm{kg}$ at $22^{\circ} \mathrm{C} ; n=$ 20 for $100 \mu \mathrm{g} / \mathrm{kg}$ at $30^{\circ} \mathrm{C}$.

an unpaired $t$ test. All data are presented as means \pm SEM. Significance was accepted at the $p=0.05$ level.

\section{Results \\ Early life manipulations: neonatal body temperature measurements}

In four different groups of rat pups, baseline temperatures were identical for all treatment groups whether the ambient temperature was 22 or $30^{\circ} \mathrm{C}$ (ANOVA, $p>0.05$ ). None of the groups displayed the stress-induced fever after the injection that is normally seen in adult rats. Body temperature responses to E. coli LPS varied as a function of LPS doses and ambient temperature (Fig. 1). Although $50 \mu \mathrm{g} / \mathrm{kg}$ E. coli LPS elicited $\sim 1^{\circ} \mathrm{C}$ fevers at both 22 and $30^{\circ} \mathrm{C}$, responses to $100 \mu \mathrm{g} / \mathrm{kg}$ LPS differed as a function of ambient temperature. At $30^{\circ} \mathrm{C}$, pups developed a robust fever after a latency of $2 \mathrm{hr}$; it peaked $\left(1.5^{\circ} \mathrm{C}\right)$ at $\sim 3 \mathrm{hr}$, and the temperatures had returned to baseline by $6 \mathrm{hr}$. In contrast, $100 \mu \mathrm{g} / \mathrm{kg}$ LPS at $22^{\circ} \mathrm{C}$ caused hypothermia, which had both latency and a nadir slightly earlier than the febrile responses seen to the same dose of LPS at the higher ambient temperature. On the basis of these results, all subsequent experiments used $100 \mu \mathrm{g} / \mathrm{kg} \mathrm{E}$. coli LPS at $30^{\circ} \mathrm{C}$ for neonatal pup treatment unless otherwise indicated.

\section{Neonatal exposure to LPS attenuates the febrile response in adulthood}

As can be seen in Figure 2, baseline temperatures of adult rats at 2-3 months of age were identical whether their neonatal treatment had been saline or LPS (ANOVA, $p>0.05$ ). All rats displayed the expected stress-induced fever that peaked at $\sim 30 \mathrm{~min}$ after the injection. In LPS-injected rats but not saline-injected rats, this was followed by an increase in body temperature regardless of the neonatal treatment. However, the magnitude of the febrile response to LPS differed as a function of neonatal treatment. In adult rats, LPS fevers were significantly attenuated if the rats had been neonatally treated with LPS rather than saline (Fig. 2) [mean peak values, $38.16 \pm 0.24^{\circ} \mathrm{C}$ (neonatal LPS) vs $38.75 \pm$ $0.17^{\circ} \mathrm{C}$ (neonatal saline); $p<0.05$ ]. Although the data displayed in Figure 2 are from one representative group of rats, this experiment was repeated four times in different groups of rats over 3

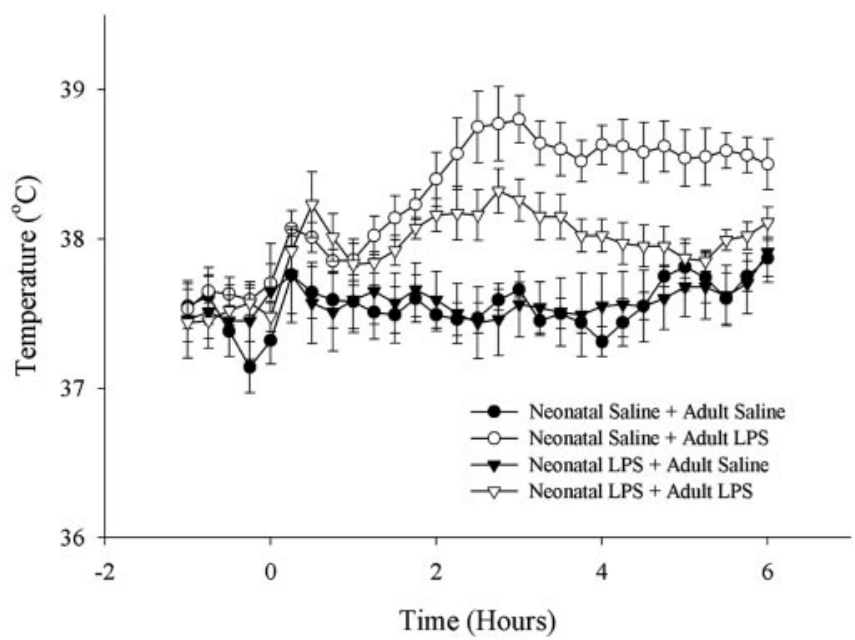

Figure 2. Body temperature responses (mean \pm SEM) to intraperitoneal LPS or saline at time 0 of adult rats treated neonatally with either saline or $E$. coli LPS. LPS fever magnitude in adult rats was significantly reduced in rats that had been treated neonatally with LPS compared with rats that had received saline in the neonatal period ( $p<0.05 ; n=6$ for each group). Adult rats given saline displayed unchanged body temperatures regardless of the neonatal treatment.

years. The fact that the results were similar each time indicates that this is a robust and reproducible response.

In contrast to the marked reduction seen in the response of adult rats treated neonatally with LPS, rats that received 100 $\mu \mathrm{g} / \mathrm{kg}$ LPS as adults and then challenged 2 months later with 50 $\mu \mathrm{g} / \mathrm{kg}$ LPS displayed fevers identical to those of controls that had been pretreated with saline alone (mean peak values, salinepretreated, $38.56 \pm 0.24^{\circ} \mathrm{C}$; vs LPS-pretreated, $38.57 \pm 0.21^{\circ} \mathrm{C}$; $p>0.05)$.

\section{The febrile response in adulthood is attenuated} independently of fever in the neonatal period

We wished to determine whether the attenuation of fever in adulthood required a neonatal fever or whether it was sufficient for the rat pups to merely be exposed to LPS. This question can be addressed because a dose of $100 \mu \mathrm{g} / \mathrm{kg}$ LPS at $30^{\circ} \mathrm{C}$ elicits a fever in neonatal rat pups whereas the same dose at an ambient temperature of $22^{\circ} \mathrm{C}$ results in hypothermia (Fig. 1). To determine whether neonatal fever resulted in attenuated fever in adulthood, we compared adult fevers of rat pups that were administered 100 $\mu \mathrm{g} / \mathrm{kg}$ LPS at either 22 or $30^{\circ} \mathrm{C}$ (i.e., fever absent or present in the neonatal period). Adult rats that had been exposed to neonatal LPS without fever displayed attenuated fevers identical to those of the pups that had been permitted to develop fevers $\left(22\right.$ vs $\left.30^{\circ} \mathrm{C}\right)$ (mean peak values, $38.25 \pm 0.26$ vs $38.16 \pm 0.17^{\circ} \mathrm{C} ; p>0.05$ ). Thus, neonatal exposure to LPS, even in the absence of febrile hyperthermia, is sufficient to blunt fever in response to LPS in adulthood.

\section{The febrile response in adulthood is attenuated} independently of LPS origin

We wished to know whether attenuation of fever in adulthood required exposure to the same LPS in adulthood as in the neonatal period. As illustrated in Figure 3, rats administered $100 \mu \mathrm{g} / \mathrm{kg}$ LPS of either E. coli or S. enteritidis origin in the neonatal period had equally attenuated fevers in response to E. coli LPS in adulthood. Fevers in response to $E$. coli LPS were identical in these two groups in adulthood $\left(38.25 \pm 0.26\right.$ vs $\left.38.14 \pm 0.13^{\circ} \mathrm{C} ; p>0.05\right)$ 


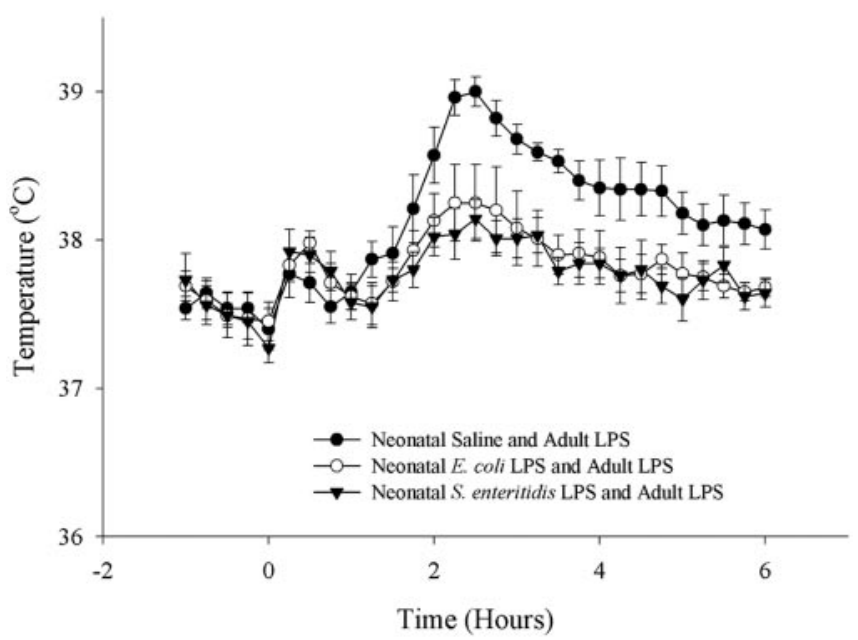

Figure 3. Body temperature responses (mean $\pm S E M$ ) to $E$. coli LPS given at time 0 of adult rats that had been treated neonatally with saline, E. coli LPS, or S. enteritidis LPS. There is no statistically significant difference in the fevers as a function of the origin of LPS given in the neonatal period ( $p>0.05$ ). Both E. coliand S. enteritidis LPS pretreatment in neonates resulted in attenuated $E$. coli LPS fevers in adults compared with the fevers of adult rats that had been treated neonatally with saline ( $p<0.05 ; n=5$ for saline; $n=6$ for $E$. coli LPS; $n=7$ for $S$. enteritidis LPS).

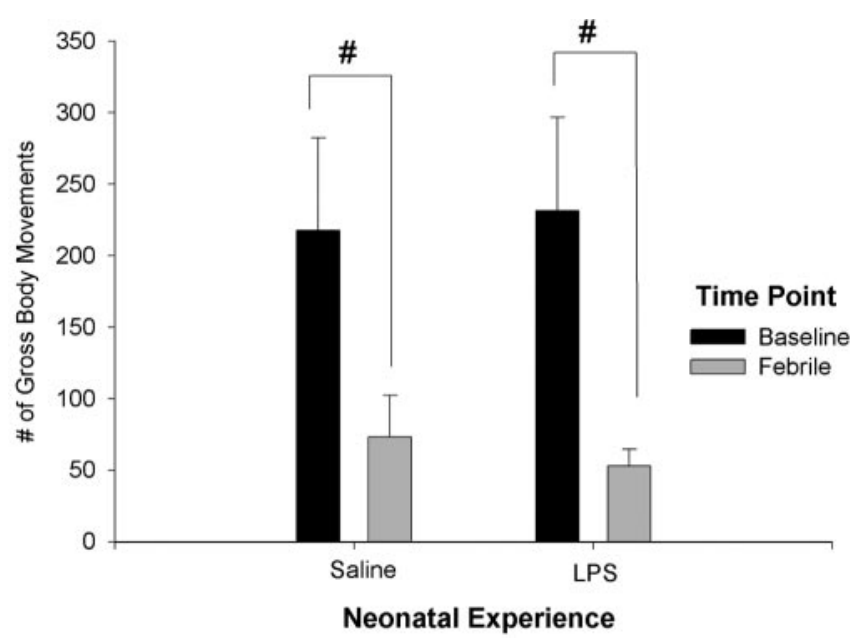

Figure 4. Activity response to $50 \mu \mathrm{g} / \mathrm{kg}$ in adult rats pretreated as neonates with either E. coli LPS or saline. Baseline values are cumulative counts over the $1 \mathrm{hr}$ period before the injection. Activity responses are the cumulative counts between hours 2 and $3\left({ }^{\#} p<0.05\right.$, paired $t$ test; $n=9$ each group). Values for both baseline and for the febrile period were unchanged ( $p>0.05$, unpaired $t$ test) as a function of the neonatal treatment.

and were both significantly lower than fevers in response to E. coli LPS of rats that were neonatally given saline (Fig. 3) (39.0 \pm $\left.0.10^{\circ} \mathrm{C} ; p<0.05\right)$. These results suggest that, regardless of the origin of LPS administered in the neonatal period, fever in response to E. coli LPS in adulthood is attenuated.

\section{Neonatal exposure to LPS does not alter LPS-induced reductions in activity during adulthood}

Before receiving LPS, adult animals of both the neonatal LPS and neonatal saline groups showed identical numbers of movements. In response to intraperitoneal injection of $50 \mu \mathrm{g} / \mathrm{kg}$ E. coli LPS, both groups of animals displayed identical reductions in activity to $\sim 25 \%$ of baseline levels (Fig. 4 ).
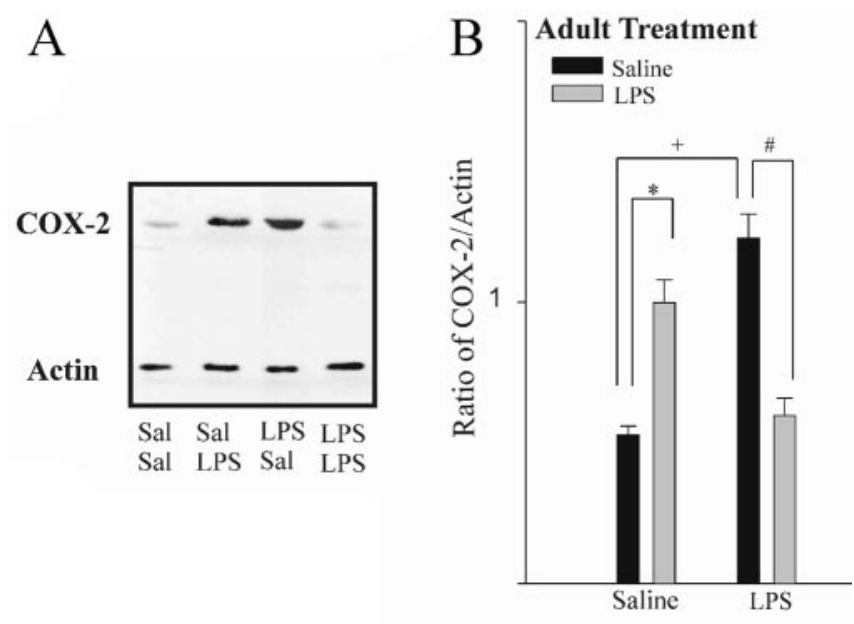

Neonatal Treatment

Figure 5. A, Sample Western blot indicating expression of COX-2 and actin in the hypothalamus of intraperitoneal saline (Sal)- or LPS-injected adult rats that had been treated neonatally with saline or LPS. B, Densitometric ratio (mean \pm SEM) of COX-2/actin from four separate experiments. Adult rats treated neonatally with saline had low basal expression of COX-2 (i.e., after an injection of saline) that increased $2.5 \mathrm{hr}$ after an injection of LPS $\left({ }^{*} p<0.05\right.$,). Adult rats treated neonatally with LPS had high basal COX-2 expression (after saline) that decreased $2.5 \mathrm{hr}$ after an injection of LPS ( $\# p<0.05)$. Basal levels of COX-2 were significantly higher in rats treated neonatally with $\operatorname{LPS}\left({ }^{+} p<0.05\right)$ than in rats treated neonatally with saline.

\section{Neonatal exposure to LPS does not alter IL-1 $\beta$ fever}

In this series of experiments, rats were again treated neonatally with either LPS or saline; as adults, the baseline body temperatures were identical in the two groups $(37.17 \pm 0.09$ vs $37.20 \pm$ $\left.0.08^{\circ} \mathrm{C} ; p>0.05\right)$. In response to $\mathrm{IL}-1 \beta$, both groups of rats developed robust fevers with a latency at $75 \mathrm{~min}$ and a peak at 130 min. There was no difference in the IL- $1 \beta$ fevers between the two groups (maximum fever, $38.49 \pm 0.14$ vs $38.59 \pm 0.08^{\circ} \mathrm{C}$; $p>0.05)$.

\section{Neonatal exposure to LPS does not alter fever in response to $\mathrm{PGE}_{2}$ in adulthood}

To test the sensitivity of neuronal prostaglandin (EP) receptors of rats treated neonatally with saline or LPS, we infused $\mathrm{PGE}_{2}$ (25 $\mathrm{ng}$ ) into the lateral cerebral ventricle of unanesthetized adult rats. From identical baseline temperatures, body temperature rose in both groups of animals to reach a peak at $\sim 30 \mathrm{~min}$ after the injection. There was no significant difference between the two groups in the peak response to $\mathrm{PGE}_{2}$ as a function of neonatal treatment $\left[\Delta 0.86 \pm 0.17^{\circ} \mathrm{C}(n=4)\right.$ vs $\Delta 0.80 \pm 0.20^{\circ} \mathrm{C}(n=6)$; $p>0.05]$. To obviate possible contributions of behavioral stress responses in contributing to the $\mathrm{PGE}_{2}$ fevers, these experiments were repeated in anesthetized rats $(n=5$, saline-pretreated; $n=$ 6, LPS-pretreated) and, again, fever heights were identical in the two groups.

\section{Neonatal exposure to LPS alters expression of hypothalamic COX-2}

Levels of COX-2 in the hypothalami of adult rats were assessed as a measure of the capacity to produce prostaglandin in response to LPS. Semiquantitative Western blot analysis indicated that adult rats treated neonatally with saline had low constitutive expression of COX-2 that increased $2.5 \mathrm{hr}$ after an injection of LPS (Fig. 5) $(p<0.05)$. In contrast, rats treated neonatally with LPS displayed elevated levels of basal COX-2 when compared with saline-pretreated littermates (Fig. 5) $(p<0.05)$. Furthermore, 
COX-2 decreased from these high levels $2.5 \mathrm{hr}$ after treatment with LPS in adulthood (Fig. 5) $(p<0.05)$ in rats treated neonatally with LPS. These differences were not attributable to changes in the amount of actin that were used to standardize the COX-2 In single blots, all actin bands $(n=8)$ had densitometry values that were within $4 \%$ of each other whether the animal had received LPS or saline as a neonate or as a challenge $2.5 \mathrm{hr}$ earlier.

\section{Discussion}

Our results show that neonatal exposure to LPS results in attenuation of the febrile response to Gram-negative pyrogens but not to IL- $1 \beta$ or to intracerebroventricular $\mathrm{PGE}_{2}$, in adulthood. In contrast, the reduction in activity that follows LPS injection was unaltered by the neonatal treatments. Furthermore, neonatal treatment with LPS results in significantly elevated basal COX-2 in the adult hypothalamus compared with saline-pretreated littermates. Most remarkable was that, whereas saline-pretreated animals displayed the expected induction of COX-2 in response to LPS administration as adults, the animals that received LPS as neonates displayed a reduction in COX-2 after LPS.

\section{Alteration in the innate immune response}

The $\mathrm{O}$ antigen portion of the LPS molecule varies from one species of Gram-negative bacteria to the next and is responsible for acquired or Ab-mediated immunity. The lipid A portion of the LPS molecule induces innate immune responses, including fever, sickness behavior, and HPA axis activation (Neter et al., 1966). This portion is highly conserved between Gram-negative species (Alexander and Rietschel, 2001). The reduction in fever and COX-2 induction that we report here may result from an alteration in the innate immune response, a novel mechanism of immunological plasticity. In support of this is the fact that neonatal administration of Gram-negative LPS from antigenically unrelated E. coli and S. enteritidis (but with similar lipid A components) results in equal attenuation of the adult febrile response to E. coli LPS.

\section{Possible mechanisms for the reduced febrile response}

The attenuation of febrile and neurochemical responses to LPS as a consequence of neonatal LPS treatment could result from a number of adaptations in the immune response. We considered the possibility that neonatally treated rats were unable to mount a thermogenic response to elicit fever. However, this would appear unlikely because our LPS-treated rats had body temperatures, as adults, identical to those of saline-treated controls, even at $22^{\circ} \mathrm{C}$, a temperature below thermoneutral for rats (Romanovsky et al., 2002). Second, both groups of animals displayed identical stressinduced fevers to the injection as adults, indicating their ability to acutely activate thermogenesis. Finally, the febrile response to both IL- $1 \beta$ and the downstream mediator PGE $_{2}$ was unaltered between LPS and control groups. These observations point to an alteration upstream to both thermoregulatory effector pathways (Nagashima et al., 2000) and the IL-1 $\beta$ (Malinowsky et al., 1995) and EP (Ushikubi et al., 1998; Nakamura et al., 2000) receptors thought to be involved in fever.

There was a marked reduction in LPS-induced levels of COX-2. COX-2 is the rate-limiting enzyme of $\mathrm{PGE}_{2}$ synthesis, and its induction is strongly correlated with $\mathrm{PGE}_{2}$ generation in the brain (Imai-Matsumura et al., 2002; Ivanov et al., 2003). This suggests that neonatally LPS-treated rats are unable to produce $\mathrm{PGE}_{2}$ or at least produce less $\mathrm{PGE}_{2}$ in their brains in response to adult LPS exposure. The mechanism responsible for the reduced COX-2 activation is still unknown. One possibility is an en- hanced HPA response to the LPS, which is known to exist in adults treated neonatally with LPS (Shanks et al., 1995; Hodgson et al., 2001). Enhanced HPA axis activation could suppress COX-2 action (and fever) via the inhibitory effect of corticosteroids, possibly through inhibition of nuclear factor $\kappa \mathrm{B}$ translocation (Auphan et al., 1995) or through inhibition of the COX-2 transcription factor activating protein 1 (Umland et al., 2002). However, an action solely at the level of COX-2 activation would be expected to interfere also with IL- $1 \beta$ action, yet IL- $1 \beta$ fevers were unchanged in the LPS-pretreated animals. Thus, a more proximal target in the cascade of cellular events would seem a more likely site of action. Glucocorticoids also block transcription of the mRNA of proinflammatory cytokines (Barber et al., 1993; Chai et al., 1996; Tatro, 2000; Franchimont et al., 2003), making it possible that there is an alteration in the profile of proand anti-inflammatory cytokines that is generated in adults after LPS. For example, either a reduction in IL- $1 \beta$ and IL- 6 or an increase in such anti-inflammatory cytokines as IL-10 (Cartmell et al., 2003) and IL-1ra (Cartmell et al., 2001) could alter the ability of LPS to activate the endothelial cells where the COX-2 is generated.

\section{Basal COX-2}

A very curious aspect of the adult response to neonatal LPS administration is the elevated level of COX-2 in the absence of LPS. Currently, we have no explanation for this. It would seem that the balance between inducible and basal COX-2 has changed in some manner. The baseline body temperatures of these animals were not elevated over those of the neonatal saline-treated animals, suggesting that they were not constitutively generating $\mathrm{PGE}_{2}$ as a pyrogen. Whether the activity of the COX-2 has changed so that it is no longer generating $\mathrm{PGE}_{2}$, or there is continuous induction attributable to an unknown stimulus in a different cellular compartment, is open to investigation. It may also be that there is a change in the profile of cells secreting inducible versus constitutive COX-2 because inducible COX-2 is synthesized primarily in perivascular endothelial cells, whereas constitutive COX-2 expression in found in neurons (Cao et al., 1997; Matsumura et al., 1998; Yamagata et al., 2001).

\section{Important aspects of the neonatal immune response}

Previous work has shown that fever is attenuated in neonatal lambs (Pittman et al., 1973) and guinea pigs (Blatteis, 1975), and neonatal rats are also known to display an attenuated response to LPS (Dent et al., 1999; Dallman, 2000). We found that, at least in $14 \mathrm{~d}$ neonatal rats, they were well able to develop a fever when maintained at a thermoneutral temperature. However, by exposing the neonates to LPS under different environmental conditions, we were able to manipulate the temperature response such that we could administer LPS to neonatal rats yet prevent the animals from developing a fever. We were thus able to ask whether the presence of fever and the realization of a critical threshold temperature in the neonates were important in the attenuated febrile response seen in the adults. However, such neonatally LPS-treated but afebrile animals showed reductions in fever in the adults that were identical to those displayed by neonates that developed a fever.

Our neonatal injections of LPS were given at a single time point, $14 \mathrm{~d}$ postnatally, an age at which we were able to allow sufficient recovery after implantation of temperature recording devices. Now that we know that fever per se is not a critical feature of the neonatal response, it will be interesting to determine whether there is a critical age for treatment. It is most likely a 
feature of the neonatal period because adult rodents subjected to repetitive injection of either LPS or of cytokines display tolerance for only a few days to weeks (Beeson, 1947), and there was no evidence of tolerance in our experiments in which adult animals were subjected to LPS at a 2 month interval. The attenuated fever response we have observed after a $2-3$ month interval also contrasts with the sensitized responses to cytokines (Hayley et al., 1999; Schmidt et al., 2001, 2003) or LPS (Hayley et al., 2001) seen after much shorter periods in adult animals. Whether the neonatal LPS exposure causes an enhanced manifestation of a response that is present in the adult, or whether it is an entirely different phenomenon, remains to be seen.

In addition to fever, LPS induces a constellation of adaptive behavioral responses, including a reduction in activity levels (Hart, 1988; Konsman et al., 2002). In contrast to the marked reductions in febrile responses of adult animals pretreated neonatally with LPS, the LPS-induced reduction in activity was unaltered. A similar dissociation between febrile and activity responses to LPS has been previously reported in a chronic model of inflammation (Boissé et al., 2003). It is possible that the immune signal activates the various components of the host defense response differently.

\section{Clinical and functional relevance}

In this study, we provide evidence that the innate immune system can be modified well into adulthood after exposure to LPS as a neonate. Our finding of attenuated fever in neonatally challenged rats sets the stage for a number of future investigations. The early activation of the neuroimmune response could alter, in the adult, the many CNS pathways and mechanisms that are known to be involved in fever as well as other autonomic and behavioral functions affected by LPS or cytokines (Oladehin and Blatteis, 1995; Elmquist et al., 1996; Tkacs et al., 1997; Dantzer et al., 1998; Zhang et al., 2000; Xia and Krukoff, 2001; Reyes and Sawchenko, 2002). These responses remain to be investigated. There are also marked gender-related differences in the responses of neonates to early manipulations (Cushing et al., 2003; El Khodor and Boksa, 2003; Park et al., 2003). For this reason, we chose to work exclusively with males. However, it will be important in future experiments to determine whether females show an identical attenuation of the response to LPS.

Most importantly, our work demonstrates how an early immune challenge in a neonate may "set the tone" for the future health of the individual as reflected by the capacity to develop fever. In particular, it would be valuable to know whether the ability to handle a bacterial infection is altered in neonatally immune-exposed animals. Because fever is such an integral part of a host's defense against infection, it may well be that any change to the febrile response could alter an animal's ability to combat infectious disease later in life. The data from our experiments lay the groundwork for such studies. Given the importance that early antigenic experience is now speculated to play in inflammatory disease states, it is likely that elucidation of the contribution of early life events in the development of the neuroimmune response could be equally important. It could provide guidance about how infection and fever should be treated in infants.

\section{References}

Alexander C, Rietschel ET (2001) Bacterial lipopolysaccharides and innate immunity. J Endotoxin Res 7:167-202.

Auphan N, DiDonato JA, Rosette C, Helmberg A, Karin M (1995) Immunosuppression by glucocorticoids: inhibition of NF-kappa B activity through induction of I kappa B synthesis. Science 270:286-290.
Barber AE, Coyle SM, Marano MA, Fischer E, Calvano SE, Fong Y, Moldawer LL, Lowry SF (1993) Glucocorticoid therapy alters hormonal and cytokine responses to endotoxin in man. J Immunol 150:1999-2006.

Beeson PB (1947) Tolerance to bacterial pyrogens. I. Factors influencing its development. J Exp Biol 86:29-38.

Blatteis CM (1975) Postnatal development of pyrogenic sensitivity in guinea pigs. J Appl Physiol 39:251-257.

Blatteis CM, Sehic E, Li S (2000) Pyrogen sensing and signaling: old views and new concepts. Clin Infect Dis 31[Suppl 5]:S168-S177.

Boissé L, Van Sickle MD, Sharkey KA, Pittman QJ (2003) Compromised neuroimmune status in rats with experimental colitis. J Physiol (Lond) 548:929-939.

Caldji C, Diorio J, Meaney MJ (2000) Variations in maternal care in infancy regulate the development of stress reactivity. Biol Psychiatry 48:1164-1174.

Cao CY, Matsumura K, Yamagata K, Watanabe Y (1997) Involvement of cyclooxygenase-2 in LPS-induced fever and regulation of its mRNA by LPS in the rat brain. Am J Physiol 272:R1712-R1725.

Cartmell T, Luheshi GN, Hopkins SJ, Rothwell NJ, Poole S (2001) Role of endogenous interleukin-1 receptor antagonist in regulating fever induced by localised inflammation in the rat. J Physiol (Lond) 531:171-180.

Cartmell T, Ball C, Bristow AF, Mitchell D, Poole S (2003) Endogenous interleukin-10 is required for the defervescence of fever evoked by local lipopolysaccharide-induced and Staphylococcus aureus-induced inflammation in rats. J Physiol (Lond) 549:653-664.

Chai Z, Alheim K, Lundkvist J, Gatti S, Bartfai T (1996) Subchronic glucocorticoid pretreatment reversibly attenuates IL-beta induced fever in rats; IL- 6 mRNA is elevated while IL-1 alpha and IL-1 beta mRNAs are suppressed, in the CNS. Cytokine 8:227-237.

Chen X, Hirasawa M, Takahashi Y, Landgraf R, Pittman QJ (1999) Suppression of PGE(2) fever at near term: reduced thermogenesis but not enhanced vasopressin antipyresis. Am J Physiol 277:R354-R361.

Coplan JD, Andrews MW, Rosenblum LA, Owens MJ, Friedman S, Gorman JM, Nemeroff CB (1996) Persistent elevations of cerebrospinal fluid concentrations of corticotropin-releasing factor in adult nonhuman primates exposed to early-life stressors: implications for the pathophysiology of mood and anxiety disorders. Proc Natl Acad Sci USA 93:1619-1623.

Cushing BS, Yamamoto Y, Hoffman GE, Carter CS (2003) Central expression of c-Fos in neonatal male and female prairie voles in response to treatment with oxytocin. Brain Res Dev Brain Res 143:129-136.

Dallman MF (2000) Moments in time-the neonatal rat hypothalamopituitary-adrenal axis. Endocrinology 141:1590-1592.

Dantzer R, Bluthe RM, Gheusi G, Cremona S, Laye S, Parnet P, Kelley KW (1998) Molecular basis of sickness behavior. Ann NY Acad Sci 856:132-138.

Dent GW, Smith MA, Levine S (1999) The ontogeny of the neuroendocrine response to endotoxin. Brain Res Dev Brain Res 117:21-29.

El Khodor BF, Boksa P (2003) Differential vulnerability of male versus female rats to long-term effects of birth insult on brain catecholamine levels. Exp Neurol 182:208-219.

Elmquist JK, Scammell TE, Jacobson CD, Saper CB (1996) Distribution of Fos-like immunoreactivity in the rat brain following intravenous lipopolysaccharide administration. J Comp Neurol 371:85-103.

Franchimont D, Kino T, Galon J, Meduri GU, Chrousos G (2003) Glucocorticoids and inflammation revisited: the state of the art. NIH Clinical Staff Conference. Neuroimmunomodulation 10:247-260.

Hart BL (1988) Biological basis of the behavior of sick animals. Neurosci Biobehav Rev 12:123-137.

Hayley S, Brebner K, Lacosta S, Merali Z, Anisman H (1999) Sensitization to the effects of tumor necrosis factor $\alpha$ : neuroendocrine, central monoamine, and behavioral variations. J Neurosci 19:5654-5665.

Hayley S, Staines W, Merali Z, Anisman H (2001) Time-dependent sensitization of corticotropin-releasing hormone, arginine vasopressin and c-fos immunoreactivity within the mouse brain in response to tumor necrosis factor-alpha. Neuroscience 106:137-148.

Hodgson DM, Yirmiya R, Taylor AN (2001) Intracerebroventricular interleukin-1beta impairs clearance of tumor cells from the lungs: role of brain prostaglandins. J Neuroimmunol 119:57-63.

Hsu FC, Zhang GJ, Raol YS, Valentino RJ, Coulter DA, Brooks-Kayal AR (2003) Repeated neonatal handling with maternal separation permanently alters hippocampal GABAA receptors and behavioral stress responses. Proc Natl Acad Sci USA 100:12213-12218.

Imai-Matsumura K, Matsumura K, Terao A, Watanabe Y (2002) Attenu- 
ated fever in pregnant rats is associated with blunted syntheses of brain cyclooxygenase-2 and PGE2. Am J Physiol 283:R1346-R1353.

Ivanov AI, Romanovsky AA, Matsumura K, Mouihate A, Clerget-Froidevaux MS, Wallace JL, Pittman QJ (2003) Near-term suppression of fever: inhibited synthesis or accelerated catabolism of prostaglandin E2? Am J Physiol 284:R860-R865.

Jiang Q, Detolla L, Singh IS, Gatdula L, Fitzgerald B, Van Rooijen N, Cross AS, Hasday JD (1999a) Exposure to febrile temperature upregulates expression of pyrogenic cytokines in endotoxin-challenged mice. Am J Physiol 276:R1653-R1660.

Jiang Q, Detolla L, Van Rooijen N, Singh IS, Fitzgerald B, Lipsky MM, Kane AS, Cross AS, Hasday JD (1999b) Febrile-range temperature modifies early systemic tumor necrosis factor alpha expression in mice challenged with bacterial endotoxin. Infect Immun 67:1539-1546.

Jiang Q, Cross AS, Singh IS, Chen TT, Viscardi RM, Hasday JD (2000) Febrile core temperature is essential for optimal host defense in bacterial peritonitis. Infect Immun 68:1265-1270.

Klein NC, Cunha BA (1996) Treatment of fever. Infect Dis Clin North Am 10:211-216.

Kluger MJ, Kozak W, Conn CA, Leon LR, Soszynski D (1998) Role of fever in disease. Ann NY Acad Sci 856:224-233.

Konsman JP, Parnet P, Dantzer R (2002) Cytokine-induced sickness behaviour: mechanisms and implications. Trends Neurosci 25:154-159.

Malinowsky D, Chai Z, Bristulf J, Simoncsits A, Bartfai T (1995) The type I interleukin-1 receptor mediates fever in the rat as shown by interleukin-1 receptor subtype selective ligands. Neurosci Lett 201:33-36.

Malkinson TJ, Cooper KE, Veale WL (1988) Physiological changes during thermoregulation and fever in urethane-anesthetized rats. Am J Physiol 255:R73-R81.

Mathew SJ, Coplan JD, Smith EL, Scharf BA, Owens MJ, Nemeroff CB, Mann JJ, Gorman JM, Rosenblum LA (2002) Cerebrospinal fluid concentrations of biogenic amines and corticotropin-releasing factor in adolescent non-human primates as a function of the timing of adverse early rearing. Stress 5:185-193.

Matsumura K, Cao C, Ozaki M, Morii H, Nakadate K, Watanabe Y (1998) Brain endothelial cells express cyclooxygenase-2 during lipopolysaccharideinduced fever: light and electron microscopic immunocytochemical studies. J Neurosci 18:6279-6289.

Meaney MJ (2001) Maternal care, gene expression, and the transmission of individual differences in stress reactivity across generations. Annu Rev Neurosci 24:1161-1192.

Mouihate A, Pittman QJ (1998) Lipopolysaccharide-induced fever is dissociated from apoptotic cell death in the rat brain. Brain Res 805:95-103.

Mouihate A, Pittman QJ (2003) Neuroimmune response to endogenous and exogenous pyrogens is differently modulated by sex steroids. Endocrinology 144:2454-2460.

Mouihate A, Chen X, Pittman QJ (1998) Interleukin-lbeta fever in rats: gender difference and estrous cycle influence. Am J Physiol 275:R1450-R1454.

Mouihate A, Clerget-Froidevaux MS, Nakamura K, Negishi M, Wallace JL, Pittman QJ (2002) Suppression of fever at near term is associated with reduced COX-2 protein expression in rat hypothalamus. Am J Physiol 283:R800-R805.

Nagashima K, Nakai S, Tanaka M, Kanosue K (2000) Neuronal circuitries involved in thermoregulation. Auton Neurosci 85:18-25.

Nakamura K, Kaneko T, Yamashita Y, Hasegawa H, Katoh H, Negishi M (2000) Immunohistochemical localization of prostaglandin EP3 receptor in the rat nervous system. J Comp Neurol 421:543-569.

Neter E, Whang HY, Luderitz O, Westphal O (1966) Immunological priming without production of circulating bacterial antibodies conditioned by endotoxin and its lipoid A component. Nature 212:420-421.

Nilsson C, Jennische E, Ho HP, Eriksson E, Bjorntorp P, Holmang A (2002) Postnatal endotoxin exposure results in increased insulin sensitivity and altered activity of neuroendocrine axes in adult female rats. Eur J Endocrinol 146:251-260.

Oladehin A, Blatteis CM (1995) Lipopolysaccharide-induced Fos expression in hypothalamic nuclei of neonatal rats. Neuroimmunomodulation 2:282-289.

Park MK, Hoang TA, Belluzzi JD, Leslie FM (2003) Gender specific effect of neonatal handling on stress reactivity of adolescent rats. J Neuroendocrinol 15:289-295.

Pittman QJ, Cooper KE, Veale WL, Van Petten GR (1973) Fever in newborn lambs. Can J Physiol Pharmacol 51:868-872.

Reyes TM, Sawchenko PE (2002) Involvement of the arcuate nucleus of the hypothalamus in interleukin-1-induced anorexia. J Neurosci 22:5091-5099.

Romanovsky AA, Ivanov AI, Shimansky YP (2002) Selected contribution: ambient temperature for experiments in rats: a new method for determining the zone of thermal neutrality. J Appl Physiol 92:2667-2679.

Schmidt ED, Schoffelmeer AN, De Vries TJ, Wardeh G, Dogterom G, Bol JG, Binnekade R, Tilders FJ (2001) A single administration of interleukin-1 or amphetamine induces long-lasting increases in evoked noradrenaline release in the hypothalamus and sensitization of ACTH and corticosterone responses in rats. Eur J Neurosci 13:1923-1930.

Schmidt ED, Aguilera G, Binnekade R, Tilders FJ (2003) Single administration of interleukin- 1 increased corticotropin releasing hormone and corticotropin releasing hormone-receptor mRNA in the hypothalamic paraventricular nucleus which paralleled long-lasting (weeks) sensitization to emotional stressors. Neuroscience 116:275-283.

Shanks N, Larocque S, Meaney MJ (1995) Neonatal endotoxin exposure alters the development of the hypothalamic-pituitary-adrenal axis: early illness and later responsivity to stress. J Neurosci 15:376-384.

Shanks N, Windle RJ, Perks PA, Harbuz MS, Jessop DS, Ingram CD, Lightman SL (2000) Early-life exposure to endotoxin alters hypothalamicpituitary-adrenal function and predisposition to inflammation. Proc Natl Acad Sci USA 97:5645-5650.

Tatro JB (2000) Endogenous antipyretics. Clin Infect Dis 31[Suppl 5]:S190-S201.

Tkacs NC, Li J, Strack AM (1997) Central amygdala Fos expression during hypotensive or febrile, nonhypotensive endotoxemia in conscious rats. J Comp Neurol 379:592-602.

Umland SP, Schleimer RP, Johnston SL (2002) Review of the molecular and cellular mechanisms of action of glucocorticoids for use in asthma. Pulm Pharmacol Ther 15:35-50.

Ushikubi F, Segi E, Sugimoto Y, Murata T, Matsuoka T, Kobayashi T, Hizaki H, Tuboi K, Katsuyama M, Ichikawa A, Tanaka T, Yoshida N, Narumiya S (1998) Impaired febrile response in mice lacking the prostaglandin E receptor subtype EP3. Nature 395:281-284.

Wachulec M, Peloso E, Satinoff E (1997) Individual differences in response to LPS and psychological stress in aged rats. Am J Physiol 272:R1252-R1257.

Xia Y, Krukoff TL (2001) Cardiovascular responses to subseptic doses of endotoxin contribute to differential neuronal activation in rat brain. Brain Res Mol Brain Res 89:71-85.

Yamagata K, Matsumura K, Inoue W, Shiraki T, Suzuki K, Yasuda S, Sugiura H, Cao C, Watanabe Y, Kobayashi S (2001) Coexpression of microsomal-type prostaglandin E synthase with cyclooxygenase-2 in brain endothelial cells of rats during endotoxin-induced fever. J Neurosci 21:2669-2677.

Zhang G, Raol YS, Hsu FC, Brooks-Kayal AR (2004) Long-term alterations in glutamate receptor and transporter expression following early-life seizures are associated with increased seizure susceptibility. J Neurochem 88:91-101.

Zhang YH, Lu J, Elmquist JK, Saper CB (2000) Lipopolysaccharide activates specific populations of hypothalamic and brainstem neurons that project to the spinal cord. J Neurosci 20:6578-6586. 